\title{
A guardiã das tradições: a História e o seu código curricular
}

\author{
The guardian of traditions: \\ History and its curricular code
}

\author{
Katia Maria Abud ${ }^{1}$
}

\begin{abstract}
RESUMO
Este trabalho estuda a permanência de conteúdos da História do Brasil nos programas escolares. Considera desde as primeiras formulações curriculares da disciplina nos programas do Colégio Pedro II até as propostas curriculares surgidas no final do século XX, para analisar a concepção da História escolar. Fundamenta-se no conceito de código curricular formulado por Raimundo Cuesta Fernández, que o entende como uma tradição social composta por ideias e princípios e por um conjunto de práticas profissionais que contribuem para fixar a História como disciplina escolar.
\end{abstract}

Palavras-chave: Didática da História; ensino de História; conteúdos de História.

\begin{abstract}
This paper studies the permanency of some contents of Brazil's History in school programs. It refers to the first formulations of curricular programs in the discipline of the Pedro II Secondary School to the curriculum proposals raised in the late twentieth century, to analyze the schools conception of History. It is based on the concept of code curriculum formulated by Raimundo Cuesta Fernández, who understands how a social tradition consists of ideas and principles and practices of a group professionals practices who help to set school history as a discipline.
\end{abstract}

Keywords: Didactic of History; History teaching; History contents.

${ }^{1}$ Doutora em História Social. Professora de Metodologia do Ensino de História e do Programa de Pós-Graduação da Faculdade de Educação da Universidade de SP. e-mail: kmabud@gmail.com 
Desde o surgimento de um campo de conhecimento identificado como História, na Antiguidade Clássica, ele vem ocupando um lugar definido na formação dos jovens. Quando as formas de educação existentes eram reservadas exclusivamente aos jovens da elite, a História que lhes era ensinada visava à sua formação como prováveis futuros líderes militares e chefes de governo. Por isso, ao conhecimento histórico se atribuíam objetivos relacionados à oratória, à ordenação, à memória e à formação moral dos sujeitos. A persistência de tais objetivos é notada nos relatos medievais, que nos contam sobre a formação dos jovens no período e no próprio quadro de disciplinas das primeiras universidades no mundo ocidental. Fundamentada na história bíblica, a construção de uma memória histórica oficial foi paginada pelo Estado e pela Igreja, mantidos que foram seus objetivos originais por todo o período moderno (CUESTA FERNÁNDEZ, 1997, p. 20).

O surgimento e o desenvolvimento da burguesia, a partir do final do século XVIII, estenderam o alcance da escolaridade aos jovens daquela classe, ao mesmo tempo em que se expandiam as escolas organizadas, fossem as de primeiras letras, fossem as secundárias, que se consolidaram já no início do século XIX, quando a História passou a ter um lugar especifico no currículo e um código curricular definido. De acordo com Raimundo Cuesta Fernández (1997), código disciplinar se entende como uma tradição social composta por ideias e princípios (científicos, pedagógicos, políticos etc.) sobre o valor da matéria de ensino e por um conjunto de práticas profissionais que contribuem para fixar a imagem social da História como disciplina escolar.

Tanto o lugar específico no currículo como o código disciplinar se definiram pelos interesses da burguesia. De acordo com Furet, o surgimento da História como campo de conhecimento coincidiu com a expansão do nacionalismo no continente europeu e com a imposição de se fazer a genealogia da nação. Como método científico e como concepção de evolução, ela se desenvolveu buscando o fortalecimento do Estado, tido como a conformação material da nação (FURET, s/d., p. 193).

No Brasil, ainda na primeira metade do século XIX, tiveram início as formas institucionais de escolarização e ensino, sob a responsabilidade do Estado: as escolas de primeiras letras e o curso secundário, este materializado pela criação, em dezembro de 1837, do Colégio D. Pedro II. Nesta segunda forma de escolarização, pretendemos nos ater para colocar em discussão o ensino de História organizado pelos documentos curriculares, que iniciaram sua existência a partir de então.

A História e seu ensino, no Brasil, encontram suas raízes mais longínquas na historiografia francesa. Surgiram ao mesmo tempo e com os mesmos 
pressupostos: positividade e linearidade dos acontecimentos históricos. O nascimento da História no Brasil coincide temporalmente com o nascimento do curso secundário e a inclusão da História como uma de suas matérias ${ }^{* *}$. Alguns meses depois da criação do Colégio D. Pedro II, foi inaugurado o Instituto Histórico e Geográfico Brasileiro, que passou a congregar pensadores em busca da identidade nacional brasileira. Desse grupo saíram os primeiros professores de História para a instituição escolar.

A criação da nossa primeira escola pública é contemporânea à expansão da escola francesa, pós-Revolução. Nela encontrou o apoio necessário para a formação curricular, por meio dos programas e dos manuais didáticos.

Os programas elaborados pelos lentes do Colégio D. Pedro II, a quem cabia tal incumbência, pouco se modificavam de um ano para outro (VECCHIA, A.; LORENZ, K. M, 1998). Além de dirigir os professores do Pedro II, tinham também a finalidade de orientar os professores dos cursos preparatórios para que seus alunos conseguissem a aprovação nos exames preparados pela escola oficial para obter o certificado de conclusão do Curso Ginasial. Por isso, podemos ter os programas como uma fonte importante para entender o percurso do ensino de História, no que diz respeito às concepções predominantes na organização da matéria na escola, até a reforma da educação elaborada em 1931, conhecida como reforma Francisco Campos. A partir da criação do curso secundário seriado, as escolas passaram a ter autonomia para realizar seus próprios exames, bem como a ter seu currículo e programas produzidos pelo recém-criado Ministério da Educação e Saúde Pública.

Sem entrar na análise da disposição na grade curricular e no número de aulas de História, o que se pode perceber pela análise dos programas é a permanência de um código curricular desde o início da História na escola. Primeiramente, destaca-se a cronologia. Elza Nadai nos lembra da importância da influência francesa na criação do Pedro II na elaboração dos programas de História e na centralização do seu ensino nos manuais franceses, traduzidos ou não, para uso dos alunos.

A História pátria surgia como seu apêndice [da História da Europa Ocidental], apresentada como a verdadeira História da Civilização.

\footnotetext{
${ }^{* *}$ Segundo André Chervel, as disciplinas escolares são entidades epistemológicas relativamente autônomas e deslocam o acento das decisões, das influências e de legitimações exteriores em direção à escola, inserindo o saber por ela produzido no interior de uma cultura escolar. As disciplinas escolares se formam no interior dessa cultura, tendo objetivos próprios e muitas vezes irredutíveis às ciências de referência. (BITTENCOURT, Circe Maria F. Disciplinas escolares: história e pesquisa. In: OLIVEIRA, M. A. T. de; RANZI, S. M. F. História das disciplinas escolares no Brasil: contribuições para o debate. Bragança Paulista: EDUSP, 2003. p. 9-19.)
} 
Relegada aos anos finais dos ginásios, com número ínfimo de aulas, sem uma estrutura própria, consistia em um repositório de biografias de homens ilustres, de datas e batalhas (NADAI, 1992/1993).

Mais tarde, aproximadamente um século depois, na escola republicana a História do Brasil adquiriria uma estrutura emprestada aos programas da escola europeia, adotando dessa maneira o código curricular que vinha se estabelecendo naquele continente. Procurou-se adaptar os períodos da história nacional brasileira aos períodos da História da Civilização. A cada um dos períodos da história europeia correspondia um equivalente à do Brasil. Os programas passaram a ser compostos pela história dos indígenas americanos, correspondentes à PréHistória e Antiguidade, e a partir da chegada dos europeus e do início da colonização se aprofundavam as tentativas de aproximação com a História europeia: o Brasil colonial equivaleria a dois dos períodos da História da Civilização: ao medieval e ao moderno. Havia propostas de análise das instituições coloniais que partiam de conceitos adequados à análise da história europeia. O exemplo mais conhecido é a comparação do sistema de capitanias, criado para colonização e povoamento português em 1532, ao sistema feudal, predominante na Europa entre os séculos VI e XV. Devo enfatizar que, excetuando as situações de evidente exagero como a citada, tem prevalecido nos currículos, com curtos períodos de modificação, a mesma periodização.

Os primeiros programas de História, elaborados para o Pedro II, seguiam com rigidez as proposições de Von Martius, vencedoras do concurso do Instituto Histórico e Geográfico Brasileiro, que indicavam como se devia escrever a História do Brasil (VON MARTIUS, 1845). Seguiam as indicações do pesquisador europeu, mas já elaboradas pelo trabalho de Francisco Adolfo Varnhagen, na História Geral do Brasil, em 1857, que por sua vez foi modelo para os programas da disciplina História do Brasil no colégio. Os primeiros livros didáticos produzidos pelos professores do Pedro II seguiam a mesma forma de organização dos conteúdos. Em relação à História Universal, os idealizadores do Colégio admitiam que havia sido necessário buscar no exterior a experiência que faltava aos dirigentes nacionais. Por esse motivo, impôs-se o modelo francês - cujos compêndios foram traduzidos para uso dos estudantes brasileiros (NADAI, 1992/1993).

A produção histórica brasileira herdou seus elementos constitutivos da historiografia francesa e os adequou à necessidade de construção da identidade nacional brasileira. Segundo Furet, no início de sua construção como conhecimento a história era tida como "a árvore genealógica das nações europeias e da civilização de que são portadoras” (FURET, s. d., p. 136). A ideia de nação, no 
contexto intelectual e político do século XIX, enlaçada à de cidadania, se embasava na crença de uma identidade comum dos indivíduos de variados grupos étnicos e/ou classes sociais. A história dos grupos dominantes, política e economicamente, seria necessariamente a mesma daqueles que eram por eles governados. Aliava-se ainda à concepção de história dominante a narrativa dos feitos daquela classe, comprovados pelos documentos (únicas fontes admitidas) que os mesmos protagonistas produziam.

Nesse contexto, nasceu a História como disciplina escolar. Os programas de estudo traziam a mesma datação e a seleção dos fatos a serem estudados era feita a partir das listas de acontecimentos selecionados pelos historiadores acadêmicos, que com frequência eram os mestres escolares. A História escolar não nasceu no Brasil, aqui ela foi caudatária da europeia, tal como o foi na versão acadêmica. Nos rumos de institucionalização traçados, seguiu os roteiros já trilhados pelos estabelecimentos escolares na Europa e, em especial, na França.

Na primeira metade do século $\mathrm{XX}$, se assistiu à expansão das escolas secundárias no Brasil. No mesmo período, foram criadas as primeiras universidades, responsáveis pela produção da História brasileira. Apesar de terem, em princípio, além da pesquisa científica o encargo da formação dos professores secundários, a primeira foi assumida como sua função primordial, seguindo o modelo das universidades europeias. A formação de professores deveria ficar a cargo dos institutos de educação. Isto de fato ocorreu relativamente aos professores dos primeiros anos escolares. Os professores especialistas nas disciplinas curriculares do ensino secundário eram formados pelos cursos universitários. Completavam a formação pedagógica nos institutos de educação, nos anos iniciais de funcionamento das universidades brasileiras.

O desenvolvimento do ensino de História no curso secundário não correu paralelamente ao dos cursos universitários, que trouxeram para a pesquisa as inovações de grupos de historiadores europeus, como ocorreu na Universidade de São Paulo, cujo curso de História contou com a presença de historiadores dos Annales.

O sistema de ensino dominante desde a criação da primeira escola secundária oficial, que vigorou até 1931, ano da Reforma Francisco Campos (Decreto 19.890/31), manteve, até aquela data, o Colégio Pedro II como escola padrão, da qual saíam os programas para todos os exames, para eliminação das cadeiras e obtenção do certificado de conclusão do curso. A Reforma Francisco Campos transformou radicalmente o sistema de ensino e deu às escolas secundárias reconhecidas oficialmente autonomia para expedir seus próprios diplomas de conclusão do curso secundário e aos sistemas escolares estaduais a autorização para elaborar seus próprios programas. Este fato não trouxe 
grandes mudanças. A leitura dos programas elaborados pelas escolas estaduais autônomas não fugia aos cânones já consagrados pelo Pedro II, mantendo para o ensino secundário as concepções de História que vinham do século anterior, que continuavam a ser do interesse das elites governantes.

A expansão da escola secundária era considerada de importância capital para a formação de setores da sociedade que estavam em expansão, como as classes médias urbanas. A escolarização seria um instrumento de preparação das novas camadas dirigentes, dos cidadãos que iriam governar o país. A escola deveria transmitir um tipo de saber civilizatório, para formar "aquela categoria social que fica entre o povo e os dirigentes do país, tanto na política como na ciência. As ideias, por meio deles, filtram-se, descendo continuamente das camadas superiores até os mais humildes: são eles que mantêm coeso o corpo da nação" (NADAI, 1988, p. 235).

A História da Civilização passou a incorporar toda a História que conhecemos como geral, mais ainda a História da América e do Brasil, distribuindo os conteúdos igualmente por todas as séries do curso ginasial, então em número de cinco. Divididos em itens I e II, o primeiro listava os conteúdos da História europeia e o segundo os conteúdos de História do Brasil e da América, que ficavam em nítida desvantagem quanto ao tempo disponível para seu ensino. Essa distribuição, segundo Amélia Domingues de Castro (1955), pretendia "estabelecer uma estreita vinculação entre o estudo do passado nacional e americano com o passado europeu". Contudo, demonstrava a concepção predominante em relação à História e ao seu ensino: não existiria para nós, se não fosse precedida da História do Ocidente com algumas poucas inserções do Oriente Próximo.

As reformas curriculares que sucederam à Reforma Campos, entre as quais se destaca, pela sua amplitude, a realizada pelo Ministro da Educação do Estado Novo, Gustavo Capanema, em 1942, não modificaram os aspectos essenciais dos programas de História para o curso ginasial: a relação de "subalternidade" da História do Brasil em relação à História da Europa Ocidental; a permanência da linha do tempo e da sequência cronológica na organização dos conteúdos e a predominância dos conteúdos de natureza política, secundarizados pelos fatos da História Econômica.

A Lei 4.024/61, de Diretrizes e Bases da Educação Brasileira, alterou a organização curricular em todos os seus sentidos: criou e eliminou disciplinas, alterou sua distribuição pelas diferentes séries e modificou a carga horária de cada uma delas. As disciplinas escolares relativas às Ciências Humanas sofreram cortes que as mutilaram para atender às necessidades provocadas pela entrada de disciplinas profissionalizantes no currículo - História e Geografia perderam 
espaço em uma das séries do curso ginasial: não se ensinava História na $3 .^{\mathrm{a}}$ série e não se ensinava Geografia na 4. ${ }^{a}$ série. Influenciados por ideias da Escola Nova, tendência pedagógica que se desenvolvera a partir das primeiras décadas do século XX, os programas escolares se curvaram aos cânones e ao predomínio das ideias da Psicologia da Educação como bases de apoio para a distribuição dos conteúdos. Houve então uma troca de conteúdos e nas primeiras duas séries passou-se a ensinar a História do Brasil e na $4 .^{a}$ série ginasial distribuiu-se a chamada História Geral.

Uma década após a promulgação da Lei 4.024, nova legislação atingia a educação, trazendo novamente mudanças estruturais por meio da Lei 5.692/ 71. O curso ginasial foi incorporado ao curso primário e com isso foi criado o curso integrado de primeiro grau. História e Geografia desapareciam como disciplinas independentes e seus conteúdos surgiam diluídos nos conteúdos de uma nova disciplina imposta ao primeiro grau: Estudos Sociais. Como os sistemas escolares estaduais gozavam de uma relativa autonomia quanto à organização e à distribuição curricular, cada Estado brasileiro buscou soluções próprias para a implantação da Lei 5.692/71. De modo geral, rejeitava-se Estudos Sociais como disciplina das últimas quatro séries do primeiro grau, pois entendia-se que, ao retirar de História e Geografia a autonomia como disciplina escolar, seus métodos de produção de conhecimento também seriam excluídos do seu ensino. Que o ensino de História fosse produzido como o conhecimento cientifico era o desafio que grupos de professores enfrentavam no magistério. A concepção da disciplina escolar como produtora de conhecimento novo se tornou um ponto de concordância, na medida em que se consideravam os suportes pedagógicos como auxiliares não somente na construção do conhecimento escolar, mas também na produção de conhecimento. $\mathrm{O}$ ensino de História, pensava-se, poderia trazer novos aportes ao conhecimento histórico e os seus métodos de ensino poderiam ser métodos de produção de conhecimento.

Os contornos da História continuaram, porém, definidos na mesma linha cronológica que tinham traçado a organização dos programas do Pedro II. Mesmo quando, com o início do processo de redemocratização em meados dos anos 1980, despontaram propostas curriculares com formas de organização de conteúdos inspiradas em diferentes correntes de pensamento, ora priorizando o cotidiano como tema, ora as formas econômicas ou as sociais, notou-se a permanência das formas de periodização que vinham do século XIX. A permanência da periodização também é um fato a ser notado nos Parâmetros Curriculares Nacionais e nas mais recentes propostas estaduais (sempre lembrando das honrosas exceções). 
Jean Chesneaux (1984), ao propor o presente como ponto de partida para reconstrução do passado, analisa a periodização da História tal como a conhecemos - Pré-História, História Antiga, História Medieval, História Moderna e Contemporânea - e que inspirou nossos historiadores ao periodizarem a História do Brasil. Lembra-nos que a periodização foi elaborada no século XIX para atender aos interesses da escola burguesa e moldar o pensamento dos jovens estudantes, para quem aquela História era produzida.

A divisão em períodos (que os programas não conseguem romper) preconiza a existência de uma única forma de história, que se representa na História Política. Ao assumir os marcos divisórios de fatos políticos, toda a narrativa passa a ser conduzida por eles, mesmo quando se inserem temas da História Econômica, Social, da Arte, entre outros. O peso de conhecimentos que se tornaram obrigatórios por força da tradição escolar vem, dessa forma, anulando as possibilidades de inovação no ensino de História. Ao obedecer às regras impostas por um código curricular que aglutina as formas consagradas e vem fechando as possibilidades de renovação, cada vez mais a História se consagra como guardiã das tradições.

\section{REFERÊNCIAS}

CASTRO, Amélia Domingues de. A História no curso secundário brasileiro. Revista de Pedagogia, São Paulo, v. 2, n. 1, p. 57-78, jan.-jun. 1955.

CHESNEAUX, Jean.?Hacemos tabla rasa del pasado? A propósito de la historia y de los historiadores. Buenos Aires: Siglo veintiuno editores, 1984.

CUESTA FERNÁNDEZ, Raimundo. Sociogenesis de una disciplina escolar: la História. Barcelona: Ediciones Pomares-Corredor, 1997.

FURET, François. A oficina da história. Trad. Adriano D. Rodrigues. Lisboa: Gradiva, s/d.

NADAI, Elza. A ideologia do progresso e o ensino superior brasileiro. São Paulo: Loyola, 1988.

. O ensino de História no Brasil: trajetória e perspectiva. Revista Brasileira de História, São Paulo, v. 13, n. 25-26, p. 143-162, set. 92/ago. 93.

SCHMIDT, Maria Auxiliadora. História com pedagogia: a contribuição da obra de Jonathas Serrano na construção do código disciplinar da História no Brasil. 
Revista Brasileira de História, São Paulo: ANPUH, v. 24, n. 48, p. 189-212, jul.-dez. 2004. (Produção e Divulgação de Saberes Históricos e Pedagógicos.)

VECCHIA, Ariclê; LORENZ, Karl Michael. Programa de Ensino da Escola Secundária Brasileira (1850-1951). Curitiba: s/e., 1998.

VON MARTIUS, Karl. Ph. Como se deve escrever a história do Brasil. Revista do Instituto Histórico e Geográfico Brasileiro, Rio de Janeiro, v. 6, n. 24, p. 381-403, 1845.

Recebido em 05 de abril de 2011.

Aprovado em 18 de junho de 2011. 
